\title{
Smoking as a risk factor for periodontitis: A literature review
}

\section{Tabagismo como um fator de risco para periodontite: Uma revisão de literatura}

\begin{abstract}
Smoking is an important risk factor for periodontitis. The high prevalence of smokers in any population makes smoking a feasible target for intervention in public health. The magnitude of the associated risk between smoking and periodontitis varies among studies, and this variation is the result of the case definition adopted rather than the limitations of the population studies. A MEDLINE search was used to identify previous publications, and a literature review was developed based on the selected articles. Smoking was consistently identified as a risk factor for periodontitis, but the risk estimates varied between studies. The comparison of risk estimates between studies was affected by the lack of uniformity for case definitions of periodontitis and smoking status.
\end{abstract}

Key words: Smoking; periodontitis; periodontal disease; risk

\section{Resumo}

O tabagismo é um importante fator de risco para periodontite. A alta prevalência de fumantes em qualquer população torna o hábito de fumar um alvo possível para intervenção em saúde pública. A magnitude do risco associado entre tabagismo e periodontite varia entre os estudos na literatura e esta variação é o resultado mais de uma definição do caso que de limitações dos estudos populacionais. Uma busca na base MEDLINE foi realizada para identificar publicações anteriores e a revisão de literatura foi desenvolvida baseada em artigos selecionados. $O$ tabagismo foi identificado consistentemente como um fator de risco para periodontite, mas as estimativas de risco variaram entre os estudos. A comparação das estimativas de risco entre estudos foi afetada pela falta de uniformidade das definições de casos de periodontite e de condições de tabagismo.

Palavras-chave: Tabagismo; periodontite; doença periodontal; risco

\section{Shaju Jacob $\mathbf{P}$ a}

a Chhattisgarh Dental College and Research Institute, Sundra, Rajnandgaon, Chhattisgarh, India

\author{
Correspondence: \\ Shaju Jacob P \\ Chhattisgarh Dental College and Research Institute \\ Sundra, Rajnandgaon \\ Chhattisgarh - India \\ 491441 \\ E-mail:shajujacob@yahoo.com
}

Conflict of Interest Statement: The authors state that there are no financial and personal conflicts of interest that could have inappropriately influenced their work.

Copyright: (C) 2010 Jacob P; licensee EDIPUCRS. This is an Open Access article distributed under the terms of the Creative Commons Attribution-NoncommercialNo Derivative Works 3.0 Unported License. 


\section{Introduction}

Smoking tobacco has been directly related to a variety of medical problems, including cancer, low birth weight, and pulmonary and cardiovascular diseases (1). Smoking appears to be one of the most significant risk factors in the development and progression of periodontal disease $(2,3)$. In India (1), $32.7 \%$ of males are smokers, while in the United States (US) (3), approximately $25 \%$ of the adult population smokes cigarettes. Less education $(4,5)$, lower socio economic status (6), increasing age (5), and rural residence (5) are associated with smoking. With a high prevalence of smokers in many countries $(7,8)$, the association between cigarette smoking and periodontal diseases presents as a significant public health problem.

\section{Methods}

The objective of this literature review was to identify studies linking smoking with periodontitis. A MEDLINE literature search was conducted using the keywords "smoking" and "tobacco" in combination with "periodontitis" or "periodontal disease". Searches were limited to the English language, and the primary focus was on current literature (1994-2009). Out of a total 1797 publications, 362 were selected based on the methodology as determined from information contained in the abstract. Cross-sectional, case-control and longitudinal studies were selected over case reports, case series and in vitro studies. After assessing the selected studies, a final subset of 42 published studies was selected for the review based on methodology, including sampling and study design. Based on study design, this review classifies the available evidence as cross sectional, case control or prospective.

\section{Evidence from cross-sectional surveys}

The National Health and Nutrition Examination Survey (NHANES) III (9) was a national health survey of the US employing a complex multistage probability sampling with oversampling of underrepresented populations like nonHispanic Blacks and Mexican Americans. An odds ratio (OR) of 3.58 with a dose-response relation for smoking frequency and duration was found in the NHANES data analysis by Tomar and Asma (9). The OR of heavy smokers (7.9) were approximately twice that of light smokers (4.2) in a survey of Thai adults (10). In a Thai survey (11), smoking had odds of 4.4 for severe periodontitis. An Australian survey (12) measured the prevalence ratio (PR) as the risk estimate because the prevalence of periodontitis was high $(23 \%)$. After adjusting for age and other risk indicators, the Australian survey recorded a PR of 1.6 for smokers. In a Japanese survey (13), smoking affected persons aged 40 and above and gave an OR of 1.4 in a multivariate analysis. In a cross-sectional survey in Brazil, Susin (14) found an odds ratio of 6.8 for heavy smokers.

When periodontitis was defined by mean loss of attachment (LOA) in NHANES III (15), a monotonic dose-response pattern was seen for current smokers with a peak adjusted OR of over 18 for the most severe categories of LOA in each age range. In a cross-sectional survey (16) on aggressive periodontitis, light smoking carried no significant risk, but the adjusted odds for heavy smoking were 3.1. In a sample from a broadly defined population (17), including a wide range of periodontal disease severity, heavy smokers had twice the odds of light smokers for developing periodontitis. The odds remained valid when the data were controlled for age and plaque.

In a cross-sectional survey (18) of 1984 subjects, age alone explained the greatest amount of variation in the regression analysis. Being over 30 years of age carried odds of 5.3 (adjusted), while smoking had odds of 1.8. A survey on rural Sri Lankans (19) also found age to be the most important contributor ( $45.4 \%$ of variation) to periodontitis development in a model explaining the variation in periodontitis. The quantity of tobacco consumed explained $9.7 \%$ of the variation, whereas smoking did not contribute to the prevalence of periodontitis. This model was true even when controlled for oral hygiene.

One cross-sectional study (20) recruited 766 subjects to examine the effect of smoking in young persons with periodontitis. The subjects included probands diagnosed with early onset periodontitis (EOP) and their immediate family members. They were classified into four categories as having healthy periodontium, adult periodontitis (AP), localized EOP, and Generalized EOP (G-EOP). The prevalence of smoking was similar in healthy individuals and those with localized EOP, while G-EOP (43\%) and AP $(38 \%)$ had a significantly greater prevalence of smoking than the other two groups. When disease status, defined by attachment loss, was compared among the groups, the smokers with G-EOP and AP had significantly more loss than the nonsmokers within the same groups. In a crosssectional study (21) of 889 subjects with mild and advanced periodontitis in Spain, smoking status was compared with periodontal status. Daily cigarette consumption had a doseresponse effect on gingival recession (GR), probing depth (PD), clinical attachment level (CAL), and mobility. Tobacco consumption had a dose-response effect on CAL across all ages. A cross-sectional study (22) by Alpagot examined 117 adults older than 18 years of age $(36 \pm 11.3$ years) in a racially diverse urban population. Within that group, Alpagot identified age, race, smoking pack/years, beta glucuronidase $(\beta \mathrm{G})$, neutrophil elastase (NE), myeloperoxidase (MPO), $F$. nucleatum, $P$. gingivalis, and $P$. intermedia as risk indicators for periodontitis.

However, the Trials to Enhance Elders Teeth and oral Health (TEETH) trial (23) of US elders failed to demonstrate any relation between smoking and periodontitis. In that trial, only smoking for more than 30 years made the relation significant (OR 1.8). A survey (24) of school students also failed to show any significant effect of smoking on periodontium. In a large Finnish survey (25), there were only small differences between smokers and nonsmokers. For smokers, the risk ratio for having one or more periodontal pockets was 1.39 . 
Former smokers have a risk estimate in between smokers and nonsmokers, and the risk decreases with the number of years after quitting. NHANES III (9) gave a risk of 3.22 for former smokers who quit within 2 years, but the risk reduced to 1.15 for quitters of $\geq 11$ years. In the Australian survey (12), former smokers recorded odds of 1.2. In the TEETH survey (23), former smokers had no estimated risk for periodontitis.

Periodontitis was attributable to smoking in $74.8 \%$ of current smokers, $64.2 \%$ for current smokers of $\leq 9 \mathrm{cig} /$ day, and $83.0 \%$ for smokers of $\geq 31 \mathrm{cig} /$ day in NHANES III 9 . In the entire US population, $52.8 \%$ of periodontitis was attributable to smoking (41.9\% and $10.9 \%$ for current and former smokers, respectively). In Australia, the populationattributable fractions (PAFs) of smoking were 32\% and 56\% for moderate and severe periodontitis, respectively (12). In the NHANES III (15), the smoking-attributable fraction of periodontitis, defined by mean LOA, for current smokers was almost $82 \%$ in the 20-49 age group and near $84 \%$ among those aged 50 years or more; the PAFs were $60 \%$ and $47 \%$, respectively. The lower PAF associated with current smoking among those aged 50 years or more (47\%) likely reflects the decreased prevalence of smoking and the greater prevalence of severe periodontal disease seen in older individuals.

The NHANES III (26) also analyzed the effects of passive smoking or environmental tobacco smoke (ETS) on periodontitis. The unadjusted odds of having periodontal disease were 1.41 times greater for persons exposed to ETS than for persons not exposed to ETS $(95 \% \mathrm{CI}=1.05,1.90)$.

\section{Evidence from case-control studies}

Very few case-control studies have examined the risk of smoking on periodontitis. Kerdvongbundit et al. (27) performed a case-control study of 60 smokers and 60 nonsmokers who had regular dental appointments and similar gingival health and oral hygiene. They demonstrated that smoking was significantly associated with poor periodontal health in terms of probing depth, clinical attachment level and gingival recession. In an age- and sex-matched casecontrol study (28) of dental patients, smoking gave odds of 3.08 for periodontitis. The odds increased to 4.95 when the data were controlled for plaque and age. A study (29) comparing established and nonestablished periodontitis patients identified a greater number of smokers in the established periodontitis group. In a multivariate analysis, smoking gave odds of 2.7 , and smoking more than 30 cigarettes a day had a risk of 12 .

A case-control study (30) attempted to analyze the effect of varying case definitions by varying the cutoff value for probing depth and the extent of sites involved. It found that risk estimates throughout were statistically significant. The estimates increased with increasing cigarette consumption, duration (years) of smoking and lifetime exposure to cigarette smoke for critical probing depths of both $5 \mathrm{~mm}$ and $6 \mathrm{~mm}$ for varying proportions of extent. The OR increased from 2.3 to 9.6 as the case definition became more stringent. A casecontrol study (31) of smokers matched with nonsmokers for age, sex and plaque levels found odds of 5.3 to periodontitis using a case definition of mean probing depth (PD) $\geq 3.5 \mathrm{~mm}$. Statistically significant differences were identified between smokers and the nonsmoker subsample for the percent of subjects with at least one site having a $P D \geq 3.5 \mathrm{~mm}$, a $\mathrm{PD} \geq 4.5 \mathrm{~mm}$, and a $\mathrm{PD} \geq 5.5 \mathrm{~mm}$.

\section{Evidence from prospective studies}

Bergstrom et al. (32) carried out a prospective study of 101 musicians and followed the study subjects for 10 years. Smokers and nonsmokers were similar in disease frequency at baseline in 1982, but in 1992, the association between smoking and the frequency of diseased sites was statistically significant, when controlling for age. Current smokers had a significant increase in the frequency of diseased sites as compared to significant decreases in former smokers and nonsmokers. In current smokers, there was a significant increase in disease with increasing cigarette consumption, smoking duration and lifetime exposure when controlled for age. The change in periodontal bone height over the 10 -year period was significantly different between current and former smokers, but it was not significantly different between former and nonsmokers. The 10-year change in periodontal bone height was predicted by bone height at baseline, age and current smoking; baseline bone height was the strongest predictor. Jansson and Lavstedt (33) examined 513 subjects over 20 years and demonstrated that smoking was significantly correlated to an increased marginal bone loss. The mean marginal bone level in 1990 was 0.74 (standard deviation (SD) 0.12) for nonsmokers, and it differed significantly from the corresponding measures for current and former smokers: 0.68 (SD 0.14) and 0.71 (SD 0.13 ), respectively. The mean marginal bone loss between 1970 and 1990 significantly increased by almost 50\% $(P<0.001)$ for smokers compared to nonsmokers and former smokers. The Dunedin study $(34,35)$ enrolled birth cohorts born in 1972-73 at the Dunedin Hospital as participants. The subjects were examined in their $15^{\text {th }}, 18^{\text {th }}, 21^{\text {st }}, 26^{\text {th }}$ and $32^{\text {nd }}$ years, but periodontal measurements were taken only at the last two examinations. Hashim et al. (35) examined the cohorts in their $26^{\text {th }}$ year and demonstrated that $3 / 4$ of the cohort who had smoked regularly at one or more of the examined ages exhibited more disease than nonsmokers. Additionally, the prevalence and the extent of attachment loss increased with exposure to smoking. The prevalence of $4+\mathrm{mm}$ LOA was $21.6 \%$ among the "ever smokers", $26.3 \%$ among the "long-term smokers", and 33.6\% among the "very long-term smokers". A less-pronounced gradient across the three exposure categories was observed for the prevalence of 5+ mm LOA, and it was less obvious for the prevalence of $6+\mathrm{mm}$ LOA. Two logistic regression models for $4+\mathrm{mm}$ LOA prevalence were presented. In the first model, those who smoked at 21 and 26 had twice the odds of "never smokers" for being a case (after adjustment for sex, plaque level and dental visiting pattern). In the second model, those who smoked at the ages of 15, 18, 21 and 26 had nearly three times the odds of being a case. Thomson 
and Broadbent ${ }^{34}$ examined the cohorts in their $32^{\text {nd }}$ year. The prevalence and the extent of attachment loss were greatest among the long-term smokers and other 32-year-old smokers (persons who started smoking after age 26). Attachment loss was lower among the ex-smokers and lowest among the never smokers. Those who had given up smoking after age 26 had levels of periodontal disease close to that of the never smokers. Compared with never smokers, long-term smokers (and other 32-year-old smokers) had high odds of being a case $(\mathrm{OR}=5 ; \mathrm{OR}=7.13$ with the more stringent case definition of $\geq 5 \mathrm{~mm} \mathrm{AL}$ ). The population-attributable risk (PAR) for new cases of $\geq 4 \mathrm{~mm}$ AL was $34.2 \%$, while that for the more stringent case definition of $\geq 5 \mathrm{~mm} \mathrm{AL}$ was $67.1 \%$ (meaning that two-thirds of the new cases between ages 26 and 32 were attributable to smoking).

Okamoto et al. (36) carried out a prospective study on 1,332 Japanese males (mean age 43.5) without periodontal disease at baseline. After 4 years, there was a very high incidence of periodontal disease (community periodontal index $\mathrm{CPI} \geq 3$ ) that increased with age. An effect modification between smoking and age was also found. A dose-response relationship was clearly detected in every age group according to the amount of smoking. The overall ORs adjusted for age and alcohol consumption were $1.11(0.68-1.85)$ for exsmokers, 1.26 (0.60-2.64) for those smoking 1-19 cigarettes per day, 2.01 (1.21-3.32) for those smoking 20 cigarettes per day, and 2.06 (1.23-3.48) for those smoking $\geq 21$ cigarettes per day. A dose-response relationship was clearly detected in every age group according to the amount of smoking, and linear trends for smoking effects (calculated excluding ex-smokers) were statistically significant.

In a longitudinal study (37) of 338 dentate adults, a person was classified as an incident case if a site had progressed $\geq 3 \mathrm{~mm}$ in attachment loss. The 3-year incidence was $27.5 \%$ for those with new lesions only, $11.1 \%$ for those with progressing lesions only and $20.1 \%$ for those with both. Disease progression was associated with income $<\$ 15,000$, soft-tissue reaction caused by medication, smoking cigarettes, a BANA-positive test, Porphyromonas gingivalis, and financial problems. In a longitudinal study ${ }^{38}$ examining the factors influencing attachment loss, 540 dentate adults ( $\geq 65$ years) were examined at 18,36 , and 60 months from baseline. A site that exhibited progression of $\geq 3 \mathrm{~mm}$ attachment loss was described as an incident site, and persons exhibiting progression were considered incident cases. In a multivariate model adjusting for the time intervals, smoking ( $\mathrm{OR}=1.6 ; 95 \% \mathrm{CI}: 1.2-2.0)$ was significantly associated with an increased risk for attachment loss in addition to $P$. gingivalis, missing teeth and low education. A total of 474 (20 to 60 years of age) adults were examined in 1973 and between 1988 and 1991 as part of a longitudinal study by Norderyd et al. (39) in an effort to identify factors associated with periodontal disease progression. In the multivariate logistic regression model, age (odds ratio 1.13 (CI: 1.06-1.19)), smoking (odds ratio $20.25(5.07-80.83)$ ), and $\%$ pockets $>4 \mathrm{~mm}$ (odds ratio 1.15 (1.04-1.27)) remained significantly associated with severe disease progression, defined as subjects with periodontal bone loss $>20 \%$ at $>6$ sites between examinations. In a longitudinal study (40) of 394 subjects (208 males and 186 females) aged more than 70 years, $75 \%$ of subjects exhibited additional attachment loss over a 2-year period. Significant associations were found between additional attachment loss and smoking (odds ratio 3.75) and an attachment level of $6 \mathrm{~mm}$ or more at baseline (odds ratio 2.29).

In a longitudinal study (41) of 147 male smokers and 30 male nonsmokers examined twice over 10 years, no significant difference was found between the two groups with respect to plaque accumulation and calculus deposits. Cigarette smoking was associated with a greater increase in probing depth, attachment loss, and greater tooth loss at an early age. Machtei et al. (42) longitudinally explored a variety of markers as possible periodontal risk factors in subjects free of periodontal disease. In total, 415 subjects (part of the Erie county longitudinal study) with mild or little periodontal disease were examined over a period of 2 to 5 years. Current smokers exhibited greater disease progression compared to nonsmokers.

In a longitudinal study (43) evaluating the effects of the level of cigarette consumption and smoking history on the response to active periodontal treatment and up to 7 years of supportive periodontal treatment (SPT), 74 persons who underwent all phases of periodontal treatment were studied. Past smokers (PSs) and nonsmokers (NSs) consistently exhibited a significantly greater reduction in probing depth than heavy smokers (HSs) and light smokers (LSs). Past smokers tended to have greater probing depth reduction than NSs during SPT. Likewise, LSs tended to have greater reduction in probing depth than HSs during SPT. Following all phases of therapy, the PSs and NSs had greater clinical attachment gains than HSs and LSs. In a 3 month study (44), periodontal status was compared at baseline and 3 months after periodontal treatment in a sample of 142 persons. There were no differences in mean CAL and PD at baseline by smoking status. After 3 months, there was a significant reduction in whole-mouth mean $\mathrm{PD}$, with current smokers showing less reduction $(P<0.04)$ than former and nonsmokers $(0.33 \pm 0.04,0.49 \pm 0.06$ and $0.49 \pm 0.08$, respectively). Current smokers exhibited less CAL gain than former and nonsmokers $(0.32 \pm 0.04,0.43 \pm 0.06$ and $0.39 \pm 0.08$, respectively).

Hunter et al. (45) analyzed subjects of a long-standing cohort who were examined in 1989 and 2000 (i.e., when they were aged 19-20 and 30-31 years, respectively) to examine the interrelation between smoking and periodontal measures. Mean scores for plaque and bleeding loss of attachment (LOA) were compared in smokers and nonsmokers. At age 19-20 years, smokers had significantly higher whole-mouth mean plaque scores compared to nonsmokers. Whole-mouth LA scores, overall and for both components A (probing depth) and B (recession) separately, showed very small, nonsignificant differences between smokers and nonsmokers. The relationship of plaque to smoking was very similar at age 30-31, with whole-mouth mean plaque scores being 
approximately $25 \%$ higher in smokers than in nonsmokers $(P<0.01)$. At age 19-20 years, with the exception of LA component B (recession), LA was slightly greater in smokers than nonsmokers, but none of these differences approached statistical significance.

\section{Summary and conclusion}

As proposed by Gelskey (46), smoking meets the majority of the criteria described by Hill for causation of periodontitis to varying degrees. The strength of the relationship between smoking and periodontitis depends on the criteria used to identify periodontitis and whether the effects of plaque and confounding variables are addressed. Studies in which plaque accumulation was similar in smokers and nonsmokers or was adjusted demonstrated that current smokers had deeper probing depths $(47,48)$, greater attachment loss $(17,47)$, more bone loss (17) and fewer teeth (47). A more restrictive definition of periodontitis gives a higher odds ratio and an attributable fraction of attachment loss associated with current smoking $(15,30)$. These studies and others $(17,49)$ have demonstrated a strong dose-response relationship between the amount smoked and the severity of periodontal destruction, which supports the role of smoking as a risk factor. Compared to nonsmokers, young adult smokers aged 19 to 30 years have a higher prevalence and severity of periodontitis when controlled for plaque levels (50-52). There was clear evidence (12) of a biological gradient within smokers with risk increasing with the number of cigarettes smoked; this was most apparent in the youngest and middle-aged groups. This is important because there is much less tooth loss in younger age groups, a phenomenon that can mask the true history of periodontitis, which can be measured only on teeth that are present in the mouth.
The smoking-attributable fraction for smokers $(12,13)$ is high and is highly dependent on the prevalence of smoking. Age (25) has also been identified as an effect modifier of the risk of smoking on periodontitis.

This paper did not review unpublished studies. Studies in developing countries, including India, were not reviewed because the overall quality from these regions was found to be low. This review identified certain limitations. Very few case-control studies have been published, and the calculation of sample size has been done arbitrarily without consideration of the prevalence of the risk factor. The strength of association (magnitude of risk) varies with case definitions used for periodontitis and smoking status. Hence, a comparison among studies cannot be done to identify differences in risk estimates among different populations. Most of the reviewed longitudinal studies were part of a larger study for which the objective was different from the objective of the derived analysis. This will affect the results and conclusions derived because the study design, including sampling, will have been done for the parent study.

\section{Recommendations}

More case-control studies need to be conducted in various populations with a focus on identifying the association between smoking and periodontitis. Similar case definitions for periodontitis and smoking should be used and a global consensus should be formed on this front. Though longitudinal studies are expensive, more studies should be designed to examine the effects of smoking on periodontitis. At the very least, identifying the associations with smoking should be included when prospective studies are designed. Case definition for incident and existing periodontitis should be uniform as well as the smoking status.

\section{References}

1. National Family Health Survey (NFHS-3), 2005-06: India: Volume I. International Institute for Population Sciences (IIPS) and Macro International. Mumbai; 2007

2. Burt B. Epidemiology of Periodontal Diseases, AAP position paper $J$ Periodontol 2005;76:1406-19.

3. Johnson GK. Tobacco Use and the Periodontal Patient. J Periodontol 1999;70:1419-27.

4. Venkat Narayan KM, Chadha SL, Hanson RL, Tandon R, Shekhawat $\mathrm{S}$, Fernandes RJ et al. Prevalence and patterns of smoking in Delhi: cross sectional study. British Medical Journal 1996;312:1576-9.

5. Jindal SK, Aggarwal AN, Chaudhry K, Chhabra SK, D'Souza GA, Gupta D et al. Tobacco Smoking in India: Prevalence, Quit-rates and Respiratory Morbidity. Indian J Chest Dis Allied Sci 2006;48: 37-42

6. Rani M, Bonu S, Jha P, Nguyen SN, Jamioum L. Tobacco use in India: prevalence and predictors of smoking and chewing in a national cross sectional household survey. Tobacco Control 2003;12:e4

7. Bartecchi CE, MacKenzie TD, Schrier, RW. The human costs of tobacco use. I. N Engl J Med 1994;330:907-12.

8. MacKenzie TD, Bartecchi CE, Schrier, RW. The human costs of tobacco use. II. N Engl J Med 1994;331:975-80.
9. Tomar, Asma. Smoking - Attributable Periodontitis in the United States: Findings From NHANES III. J Periodontology 2000;71: 743-51.

10. Torrungruang, Nisapakultorn, Sutdhibhisal, Tamsailom, Rojanasomith, Vanachiakvong et al. The effect of cigarette smoking on the severity of periodontal disease among older Thai adults. J Periodontol 2005;76:566-72.

11. Torrungruang, Tamsailom. Risk indicators of periodontal disease in older Thai adults. J Periodontol 2005;76:558-65.

12. Do Loc G, Gary S. Smoking attributable periodontal disease in the Australian adult population. J Clin Periodontol 2008;35: 398-404

13. Ojima M, Hanioka T, Tanaka K, Inoshita E, Aoyama H. Relationship between smoking status and periodontal condition, findings from national databases in Japan. J Periodontal Res 2006;41:573-9.

14. Susin C, Valle P, Oppermann RV, Haugejorden O, Albandar JM. Occurrence and risk indicators of increased probing depth in an adult Brazilian population. J Clin Periodontol 2005;32:123-9.

15. Hyman, Reid. Epidemiological risk factors for periodontal attachment loss among adults in the US. J Clin Periodontol 2003;30: 230-7. 
16. Susin, Albandar. Aggressive periodontitis in an urban population in Southern Brazil. J Periodontol 2005;76:468-75.

17. Grossi SG, Zambon JJ, Ho AW, Koch G, Dunford RG, Machtei EE et al. Assessment of risk for periodontal disease I. Risk indicator for attachment loss. J Periodontol 1994;65:260-7.

18. Horning GM, Hatch CL, Cohen ME. Risk Indicators for Periodontitis in a Military Treatment Population. J Periodontol 1992;63:297-302.

19. Amarasena N, Ekanayaka AN, Herath L, Miyazaki H. Tobacco use and oral hygiene as risk indicators for periodontitis. Community Dent Oral Epidemiol 2002;30:115-23.

20. Schenkein HA, Gunsolley JC, Koertge TE, Schenkein JG, Tew JG. Smoking and its effects on early-onset periodontitis. J Am Dent Assoc 1995;126:1107-13.

21. Martinez-Canut P, Lorca A, Magan R. Smoking and periodontal disease severity. J Clin Periodontol 1995;22:743-9.

22. Alpagot, Wolft. Risk indicators for periodontal disease in a racially diverse urban population. J Clin Periodontol 1996;23:982-8.

23. Persson RE, Kiyak AH, Wyatt $\mathrm{CCl}$, MacEntee M, Persson GR. Smoking, a weak predictor of periodontitis in older adults. J Clin Periodontol 2005;32:512-7.

24. Lopez, Fernandez, Jara, Baelum. Epidemiology of Clinical attachment loss in adolescents. J Periodontol $2001 ; 72: 1666-74$

25. Markkanen H, Paunio I, Tuominen R. Smoking and Periodontal Disease in the Finnish Population Aged 30 Years and Over. J Dent Res 1985;64:932-35.

26. Arbes Jr SJ, Ágústsdóttir H, Slade GD. Environmental Tobacco Smoke and Periodontal Disease in the United States. Am J Public Health $2001 ; 91: 253-7$

27. Kerdvongbundit, Wikesjo. Effect of smoking on periodontal health in molar teeth. J Periodontol 2000;71:433-7.

28. Al-Wahadni A, Linden GJ. The effects of cigarette smoking on the periodontal condition of young Jordanian adults. J Clin Periodontol 2003;30:132-7.

29. Calsina G, Ramo'n JM, Echeverrı'a JJ. Effects of smoking on periodontal tissues. J Clin Periodontol 2002; 29:771-6.

30. Bergstrom. Tobacco smoking and risk for periodontal disease. J Clin Periodontol 2003;30:107-13.

31. Stoltenberg JL, Osborn JB, Pihlstrom BL, Herzberg MC, Aeppli DM Wolff LF et al. Association Between Cigarette Smoking, Bacterial Pathogens and Periodontal Status. J Periodontol 1993;64: 1225-30.

32. Bergstrom, Eliasson, Dock. A 10 year prospective study of tobacco smoking and periodontal health. J Periodontol 2000;71: 1338-47.

33. Jansson L, Lavstedt S. Influence of smoking on marginal bone loss and tooth loss- a prospective study over 20 years. J Clin Periodonto 2002;29:750-6

34. Thomson, Broadbent. Cigarrette smoking and periodontal disease among 32 year olds: A prospective study of a representative birth cohort. J Clin Periodontol 2007;34:828-34.
35. Hashim, Thomson. Smoking in adoloscent as a predictor of early loss of periodontal attachment. Community Dent Oral Epidemiol $2001 ; 29: 130-5$

36. Okamoto Y, Tsuboi S, Suzuki S, Nakagaki H, Ogura Y, Maeda K et al. Effects of smoking and drinking habits on the incidence of periodontal disease and tooth loss among Japanese males: a 4-yr longitudinal study. J Periodontal Res 2006;41:560-6.

37. Beck JD, Koch GG, Offenbacher S. Incidence of attachment loss over 3 years in older adults - new and progressing lesions. Community Dent Oral Epidemiol 1995;23:291-6.

38. Beck JD, Cusmano L, Green HW, Koch GG, Offenbacher S. A 5 -year study of attachment loss in community-dwelling older adults: incidence density. J Periodontal Res 1997;32:506-15.

39. Norderyd, Hugoson. Risk of severe periodontal disease in a swedish adult population. A Longitudinal study. J Clin Periodontol 1999;26:608-15.

40. Ogawa, Yoshihara. Risk factors for periodontal disease progression among elderly people. J Clin Periodontol 2002;29:592-7.

41. Chen X, Wolff L, Aeppli D, Guo Z, Luan W, Baelum V et al. Cigarette smoking, salivary/gingival crevicular fluid cotinine and periodontal status. A 10 -year longitudinal study. J Clin Periodonto $2001 ; 28: 331-9$

42. Machtei. Longitudinal study of predictive factors for periodontal disease and tooth loss. J Clin Periodontol 1999;26:374-80.

43. Kaldahl WB, Johnson GK, Patil KD, Kalkwarf KL. Levels of cigarette consumption and response to periodontal therapy. J Periodontol 1996;67:675-81

44. Grossi SG, Zambon J, Machtei EE, Schifferle R, Andreana S, Genco RJ et al. Effects of smoking and smoking cessation on healing after mechanical periodontal therapy. J Am Dent Assoc 1997;128:599-607.

45. Hunter L, Newcombe R, Richmond S, Owens J, Addy M. The Cardiff Dental Survey: oral hygiene, gingival and periodontal health in relation to smoking in young adults. Int J Dent Hygiene 2008;6: 199-204

46. Johnson, Hill. Cigarette smoking and the periodontal patient, state of the art review. J Periodontol 2004;75:196-209.

47. Haffajee, Socransky. Relationship of cigarrette smoking to attachment level profiles. J Clin Periodontol 2001 ;28:283-95.

48. Medina-Solis, Nunez P. National survey on edentulism and its geographical distribution among Mexicans 18 years of age and older (with emphasis on WHO age groups). J Oral Rehab 2008;35:237-44

49. Grossi, Genco, Machtei. Assessment of risk for periodontal disease II. Risk indicator for Alveolar bone loss. J Periodontol 1995;66:23-9.

50. Haber J. Evidence for cigarrette smoking as a major risk factor for periodontitis. J Periodontol 1993;64:16-23.

51. Linden, Mullally. Cigarrette smoking and periodontal destruction in young adults. J Periodontol 1994;65:718-23.

52. Machuca, Rosales, Lacalle, Machuca, Bullon. Effect of cigarette smoking on periodontal status of healthy young adults. J Periodontol $2000 ; 71: 71-8$. 